\title{
International Workshop on High Frequency Micromagnetic Devices and Materials
}

\section{Introduction}

Current issue of The Transactions of The Magnetics Society of Japan is devoted to discuss high frequency micromagnetic devices and materials, which follows the International Workshop on High Frequency Micromagnetic Devices and Materials, held in Delft Institute of Microelectronics and Submicron Technology (DIMES), Delft University of Technology, The Netherlands, on May 3rd 2002.

Encouraged speakers at the workshop had submitted the papers to this number of The Transactions of The Magnetic Society of Japan Transactions. Those papers were subjected to the regular review processes of the Transactions based on the great helps of overseas volunteer reviewers as well as domestic reviewers. Seven papers are published in this issue, as a result.

Besides, it was a new experience for The Magnetics Society of Japan to employ electronic submission/ review processes, which helped the authors and reviewers located overseas especially. This gave a good opportunity to collect valuable knowledge to establish coming electronic submission/review system for the regular Japanese Journal as well as for the English Transactions.

This article is intended to describe such editorial issues as well as to introduce the micromagnetic devices and the assigned workshop, by the names of workshop co-chairs and publication chair.

\section{What are micromagnetic devices?}

There have been continuous efforts to develop high performance miniaturized inductors, transformers and other inductive magnetic devices, as well as the high-frequency materials and circuitry required by such devices. These engineering seeds have met a need of the latest IT devices that offer significantly huge applications for soft magnetic films as integrated passives, electromagnetic noise countermeasure, sensors, etc., in the $\mathrm{RF}$ range, especially in the $800 \mathrm{MHz}-6 \mathrm{GHz}$ range and beyond.

Physical understanding of high frequency characteristics and high speed switching properties of magnetic films, thin film material developments and sophisticated micro-fabrication/packaging techniques to complete a planar form are all required to realize such high performance miniaturized devices as well as analysis, simulation and instrumentation techniques.

Again, these will create new magnetic devices and components and integrated semiconductor circuits with resistors, capacitors and other active/passive elements, to realize micro-miniature systems with a high level of functionality.
Technologies covered in this topic are closely connected to the write head issues in HDD technologies for all aspects but they are very often discussed separately because this topic is on the interdisciplinary technology roadmaps of semiconductor IT devices and MEMS as well as on high density magnetic recording. Accordingly several different key words are used to address this topic, including micromagnetic devices, planar inductive devices, magnetic MEMS, RF integrated passives and global integration techniques.

Anyway, the based construction of such devices and techniques is the combination of a thin magnetic element and a planar/micromachined coil, and the term can refer to devices and components based on bulk materials also. Frequency range should cover below $1 \mathrm{MHz}$ to over $10 \mathrm{GHz}$. Whether in thin film or in bulk form, the goals of smaller sized, thinner shapes and thinner and higher levels of integration are the same, and research methodologies likewise have many points in common.

\section{Brief technological background}

Early works on ferromagnetic thin-film inductors and transformers were performed by Gleason ${ }^{1)}$ and Saleh ${ }^{2)}$, followed by a systematic study in Japan initiated by Shirae $^{3)}$ in 1980s and early 1990s. Ref. 4) and 5) well review basic knowledge and early days.

The idea of CMOS integrated RF inductor was innovated by Burghartz ${ }^{6-8)}$ whereas the advantage of possible CMOS integrated ferromagnetic RF inductor was demonstrated separately by Yamaguchi ${ }^{9,10)}$ and Gardner, et $\mathrm{al}^{11)}$. This workshop is located where these two technology merge.

Thin film materials technology is also a key issue on micromagnetic devices. Granular thin films ${ }^{12}$ are discussed in terms of high resistivity and large anisotropy field to eliminate eddy current losses and to get rid of ferromagnetic resonance. Films with high saturation moment benefits high permeability and high ferromagnetic resonance frequency simultaneously. As is known, maximum available moment at room temperature is $2.45 \mathrm{~T}$ of CoFe system. This workshop also deals how to get this material "soft" from different aspects ${ }^{13-16)}$.

\section{Delft international workshop on the high frequency micromagnetic devices and devices}

The structure of the workshop organization was as follows: Workshop organizer: DIMES, Delft University of Technology. Assent: The Magnetics Society of Japan, Technical Committee of Magnetics, IEE of Japan, Special committee on the advanced ultra high frequency micromagnetic devices. Workshop co-chairs: Joachim N. Burghartz (DIMES, TU Delft), Masahiro Yamaguchi 
(RIEC, Tohoku Univ.) Program co-chairs: Masahiro Yamaguchi (RIEC, Tohoku Univ.), Behzad Rejaei (DIMES, TU Delft.) Local chair: Joachim N. Burghartz (DIMES, TU Delft.) Publications chair: Toshiro Sato (Shinshu Univ.)

This workshop was scheduled on May 3rd, 2002, the day after the Intermag 2002 conference held in Amsterdam. Since the workshop was triggered only three month before it convened, all the presentations were assigned by program co-chairs as invited talks. There were 11 presentations from France, Germany, Japan, Netherlands and the United States (alphabetical order).

Firstly, the topics covered the materials development issues on ( $\mathrm{CoFeB})-\left(\mathrm{SiO}_{2}\right), \mathrm{Fe}-\mathrm{Co}-\mathrm{N}$, High-Hk $\mathrm{CoZrNb}$, $\mathrm{Ni}_{78} \mathrm{Fe}_{22}, \mathrm{Fe}_{50} \mathrm{Co}_{50} / \mathrm{Fe}_{80} \mathrm{~B}_{20}$ and electroplated ferrite thin films. Sputter deposition on a rotating/moving substrate were also discussed. While three papers discussed experimental results on $\mathrm{RF}$ integrated inductors with/without magnetic thin film, another three papers dealt with modeling of the material properties and the device design for the integrated inductors. Another two papers demonstrated transmission lines devices, followed by a unique paper on magnetostrictive LC circuits. Then the workshop was concluded with the 30-minute general discussion. Interested readers can reach the technical program at the workshop Web page ${ }^{17,18)}$.

Works by Burghartz ${ }^{6-8)}$, Wang ${ }^{13-15)}$ and Yamaguchi ${ }^{4,5),}$ ${ }^{9,10)}$ had not been submitted to this issue because their talks have already became tutorial.

Number of the workshop attendee was about 40 from countries of the presenters and also from Ireland and Belgium.

\section{Concluding remarks}

This workshop provided an opportunity to get together those who are interested in micromagnetic devices and also bridged semiconductor microelectronics techniques and applied ferromagnetic thin-film techniques, where a number of outstanding new research topics and industrial huge applications should be awaiting. It was recommended by several attendees to make efforts to find out the killer application of the devices discussed in the workshop.

There would be next occasion to convene similar workshop. Interested individuals may check the Web site $^{17)}$. Related news is an invited symposium on "RF soft magnetic films and planar inductive devices (tentative)" at Intermag 2003 conference held in Boston, the United States, during March 31st-April 3rd. Six invited speakers will discuss the RF soft magnetic materials, possible applications and simulation techniques for micromagnetic devices.

\section{Acknowledgments}

The authors are grateful to those who contributed to the workshop as speakers, attendees, authors and reviewers of the transactions papers, and the societies who backuped the workshop. Extended thanks to Dr. Behzad Rejaei and related people at DIMES, TU Delft, for leading the workshop successful on the day of convener. Special thanks to The Magnetics Society of Japan for having made a quick decision to allow us to publish the workshop papers.

\section{References}

1) F. R. Gleason, Proc. Nat. Electron. Conf., 20, 197-198(1964).

2) N. Saleh, A. H. Qureshi, Electronics Letters., 6, 850-852 (1970).

3) K. Kawabe, H. Koyama, K. Shirae, IEEE Trans. Magn., 20, 1804-1806 (1984).

4) K. I. Arai, M. Yamaguchi, IEEE Translation Journal on Magnetics in Japan, 9, 170-179 (1994).

5) M. Yamaguchi, Chapter 5 of "MAGNETIC THIN FILM DEVICES," Academic Press (2000).

6) J.N. Burghartz, D.C. Edelstein, K.A. Jenkins, Y.H. Kwark, IEEE Trans. on Microwave Theory and Techniques, 45, 1961- 1968 (1997).

7) J.N. Burghartz, M. Soyuer, K.A. Jenkins, M. Kies, M. Dolan, K. Stein, J. Malinowski, D.L. Harame, IEEE Journal of Solid-State Circuits, 32, 1440-1445 (1997).

8) J.N. Burghartz, International Journal on Microwave and Millimeter Wave CAD, 8, 422-432 (1998).

9) M. Yamaguchi, , K. Suezawa, K. I. Arai, Y. Takahashi, S. Kikuchi, Y. Shimada, W. D. Li, S. Tanabe, K. Ito, J. Appl. Phys. 85,7919 (1999).

10) M. Yamaguchi, M. Baba, K.I. Arai, IEEE Trans. on Microwave Theory and Techniques, 49 2331-2335 (2001).

11) D. Gardner, A. M. Crawford, S. X. Wang, 2001 IEEE International Interconnect Conference (IITC2001) 103 (2001).

12) H. Karamon, T. Masumoto, Y. Makino, J. Appl. Phys., 57, 3527 (1985). List of published materials available in Ref. $5)$.

13) N. X. Sun, S. X. Wang, T. J. Silva, and A. B. Kos, IEEE Trans. Magn., 38, 146-150 (2002).

14) S. X. Wang, N. X. Sun, M. Yamaguchi, and S. Yabukami, Nature, 407, 150-1 (Sept. 14, 2000).

15) N. X. Sun, A. M. Crawford, and S. X. Wang, Mat. Res. Soc. Symp. Proc., 721, 249-258 (2002)

16) A. Ludwig, M. Tewes, S. Glasmachers, M. Löhndorf and E. Quandt, J. Magnetism and Magnetic Materials, 242-245, Part 2, 1126-1131 (2002).

17) http://www.arai.riec.tohoku.ac.jp/yamaguti/delftworkshop/

18) http://www.dimes.tudelft.nl/rfworkshop.pdf

Masahiro Yamaguchi, Joachim N. Burghartz ${ }^{*}$, and Toshiro Sato ${ }^{* *}$

Research Institute of Electrical Communication (RIEC), Tohoku Univ., 2-1-1 Katahira, Aoba-ku,Sendai 980-8577, Japan

*Delft Institute of Microelectronics and Submicron Technology (DIMES), Delft Univ. of Tech., Mekelweg 4, P. O. Box 5031, 2600 GA Delft, The Netherlands

"*Faculty of Engineering, Shinshu Univ., 4-17-1 Wakasato, Nagano 380-8553, Japan 